University of South Carolina

Scholar Commons

$1-1-2004$

\title{
Design and Analysis of an R-Shaped Dual-Band Planar Inverted-F Antenna for Vehicular Applications
}

\author{
Mohammod Ali \\ University of South Carolina - Columbia, alimo@engr.sc.edu \\ Guangli Yang \\ University of South Carolina - Columbia \\ Huan-Sheng Hwang \\ Sony Ericsson Mobile Communications \\ Tuangsit Sittironnarit \\ University of South Carolina - Columbia
}

Follow this and additional works at: https://scholarcommons.sc.edu/elct_facpub

Part of the Electrical and Computer Engineering Commons

Publication Info
Published in IEEE Transactions on Vehicular Technology, Volume 53, 2004, pages 29-37.
http://ieeexplore.ieee.org/xpl/Recentlssue.jsp?punumber=25
(c) 2004 by IEEE

This Article is brought to you by the Electrical Engineering, Department of at Scholar Commons. It has been accepted for inclusion in Faculty Publications by an authorized administrator of Scholar Commons. For more information, please contact digres@mailbox.sc.edu. 


\section{Design and Analysis of an R-Shaped Dual-Band Planar Inverted-F Antenna for Vehicular Applications}

Mohammod Ali, Member, IEEE, Guangli Yang, Huan-Sheng Hwang, Member, IEEE, and Tuangsit Sittironnarit

\begin{abstract}
A dual-band R-shaped planar inverted-F antenna is proposed for vehicular application. Utilization of this unique geometry dual-frequency operation is achieved with a single feed. The proposed antenna operates in the 225 - and $450-\mathrm{MHz}$ bands. Input impedance and return loss data as function of various antenna parameters are presented, which show that parameters can be adjusted in order to obtain optimum tuning. Radiation pattern data for the antenna mounted on the roof of two types of vehicles are given. The pattern in the low-frequency band is essentially omnidirectional while that in the high-frequency band is directional and normal to the antenna surface. With proper scaling, this antenna may be suitable for dual-band GSM 900/1800-MHz phone applications.
\end{abstract}

Index Terms-Antenna, dual band, planar inverted-F antenna (PIFA), vehicular.

\section{INTRODUCTION}

$\mathbf{R}$ ECENTLY, there has been a surge of interest in planar inverted-F antennas (PIFAs) for mobile phone applications [1]-[13]. Such antennas are smaller than resonant half-wavelength long microstrip patches and can be easily hidden within the housing of a mobile phone. For a conventional PIFA, only single-band operation is possible. Examples of dual-band design can be found in [3], [5], [7], [8], and [10].

In [3]. a dual-band PIFA design was proposed that consisted of two radiating elements side by side, which were fed separately using two feeds. One of the antenna elements was larger than the other, making it suitable to resonate at $900 \mathrm{MHz}$. The smaller one resonated at $1800 \mathrm{MHz}$. Mutual coupling data for the two-feed design were also given. The paper also presented some preliminary data on a single-feed dual-band design. Another dual-feed dual-band design was proposed in [5] and a single-feed dual-band design was presented in [7]. The rectangular antenna contained a U-shaped slot that resulted in dual-band operation. In [8], several dual-band stacked PIFAs were introduced for $900-$ and $1800-\mathrm{MHz}$ cellular telephone applications. The antennas were designed and analyzed using the finite-difference time-domain (FDTD) method. In one case, a top and a bottom plate were capacitively coupled to two

Manuscript received March 11, 2002; revised November 26, 2002, March 11, 2003, June 11, 2003, and October 17, 2003.

M. Ali, G. Yang, and T. Sittironnarit are with the Department of Electrical Engineering, University of South Carolina, Columbia, SC 29208 USA (e-mail: alimo@engr.sc.edu).

H.-S. Hwang is with Sony Ericsson Mobile Communications, Research Triangle Park, NC 27709 USA.

Digital Object Identifier 10.1109/TVT.2003.822032

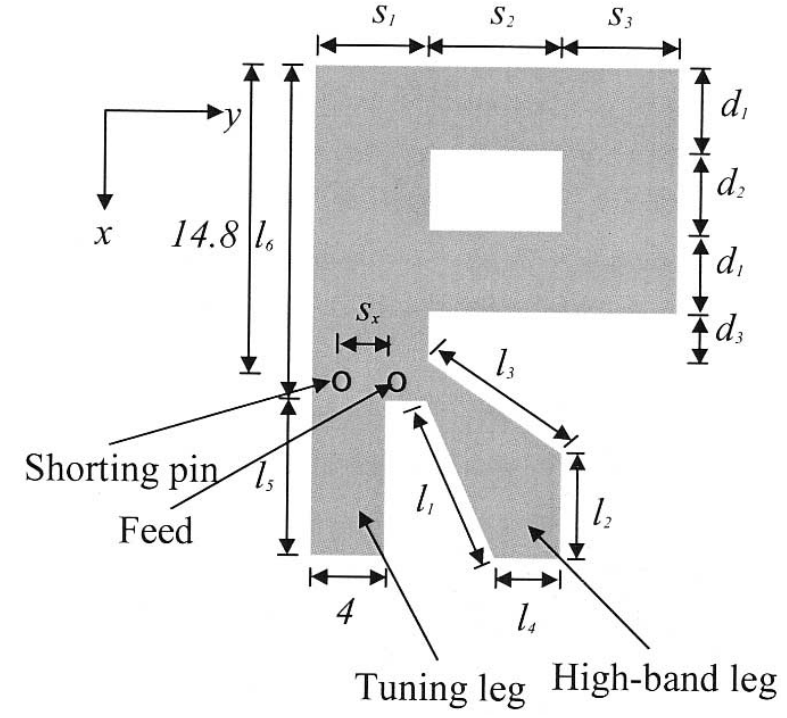

Fig. 1. Geometry of the proposed antenna (dimensions in centimeters).

feed plates. One of the feed plates was also connected to the ground plane, which acted as the shorting pin for the PIFA. In another case, the top plate was connected to the feed using a feed pin and was connected to the ground using a shorting pin. The bottom plate was capacitively connected to the top plate and the ground. In [10], two separate radiating elements (the larger for the $900-\mathrm{MHz}$ band and the smaller for the $1800-\mathrm{MHz}$ band) were both inductively and capacitively coupled to obtain dual-band performance characteristics.

Studying the above papers and other literature, it is observed that achieving dual-band performance using a single feed requires two separate radiating elements. Such elements have been shown to be connected using inductors and capacitors in [10]. We propose a new design in which the two radiating elements, when combined, create a shape resembling the letter "R." The top part of the letter with a slot represents the radiating element for the low-frequency band while the leg on the right represents the element for the high-frequency band. The straight leg provides additional means to achieve further tuning. The antenna feed is near the junction where the low- and high-frequency band elements are connected together. The advantage of the current design over existing ones is that there is no need for capacitive or inductive connection. The connection between the lowand high-frequency bands is direct. In addition, the proposed design provides further options to achieve optimum tuning by adjusting the dimensions of the slot and the tuning leg. 


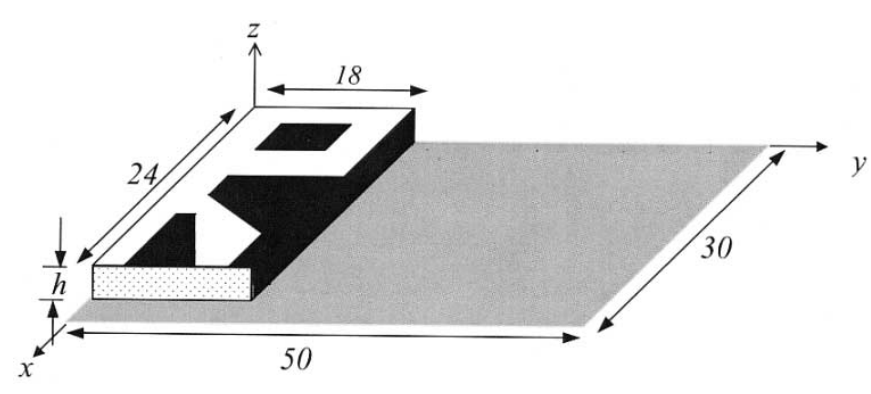

Fig. 2. Proposed antenna on a ground plane.

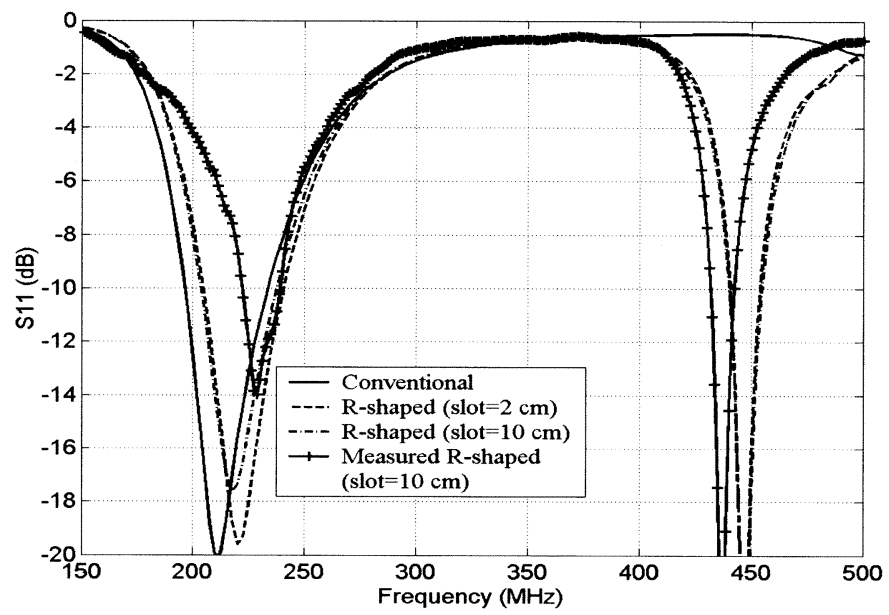

Fig. 3. Computed and measured return loss versus frequency. Other parameters are $\mathrm{h}=3.8 \mathrm{~cm}, \mathrm{~s}_{\mathrm{x}}=3.5 \mathrm{~cm}, \mathrm{~d}_{1}=4 \mathrm{~cm}, \mathrm{~d}_{2}=4 \mathrm{~cm}, \mathrm{~d}_{3}=2 \mathrm{~cm}$, $1_{1}=8.4 \mathrm{~cm}, 1_{2}=6 \mathrm{~cm}, 1_{3}=7.26 \mathrm{~cm}, 1_{4}=3.5 \mathrm{~cm}, 1_{5}=8 \mathrm{~cm}$, and $1_{6}=16 \mathrm{~cm}$.
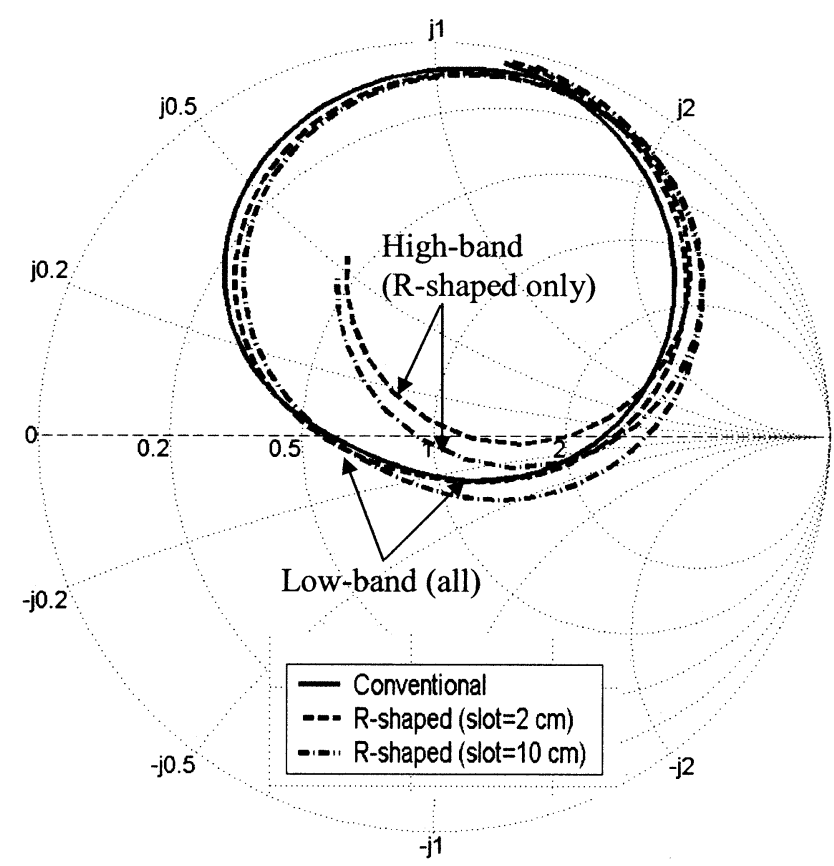

Fig. 4. Computed input impedance versus frequency. Other parameters are $h=3.8 \mathrm{~cm}, s_{x}=3.5 \mathrm{~cm}, d_{1}=4 \mathrm{~cm}, d_{2}=4 \mathrm{~cm}, d_{3}=2 \mathrm{~cm}, l_{1}=8.4 \mathrm{~cm}$, $l_{2}=6 \mathrm{~cm}, l_{3}=7.26 \mathrm{~cm}, l_{4}=3.5 \mathrm{~cm}, l_{5}=8 \mathrm{~cm}$, and $l_{6}=16 \mathrm{~cm}$.

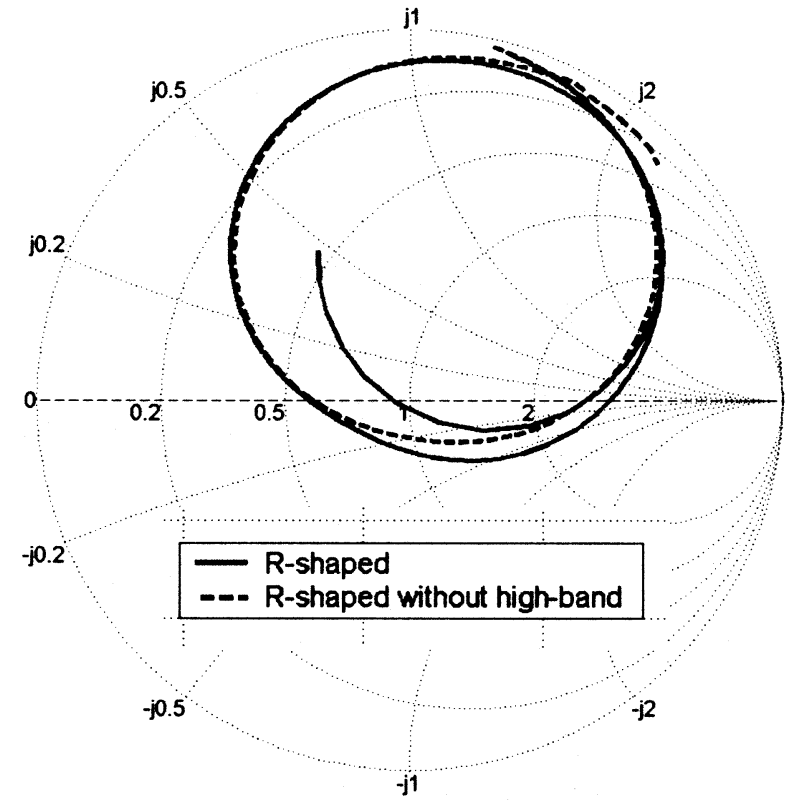

(a)

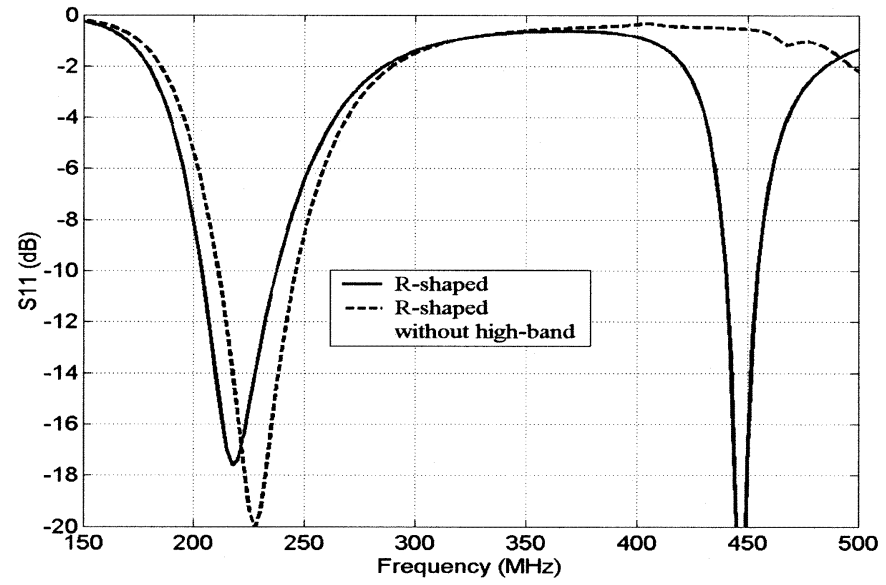

(b)

Fig. 5. Computed (a) input impedance and (b) return-loss versus frequency data for the R-shaped PIFA with and without the high-band leg. Other parameters are $s_{1}=s_{3}=4 \mathrm{~cm}, s_{2}=10 \mathrm{~cm}, h=3.8 \mathrm{~cm}, s_{x}=3.5 \mathrm{~cm}$, $d_{1}=4 \mathrm{~cm}, d_{2}=4 \mathrm{~cm}, d_{3}=2 \mathrm{~cm}, l_{5}=8 \mathrm{~cm}$, and $l_{6}=16 \mathrm{~cm}$.

In this paper, instead of focusing on mobile phone application, we propose an R-shaped PIFA design for 225/450-MHz dual-band vehicular application. One example can be UHF military application. However, the antenna design presented here does not reflect any particular military vehicle of choice. Rather the proposed antenna is modeled on a Mitsubishi Lancer Cedia and a Jeep Wrangler, which are commercially available. Nevertheless, design guidelines obtainable from the present study should apply to military vehicles as well.

For vehicular application, traditionally whip (quarter-wave or 5/8-wavelength long) antennas are used [14]. The whip being an external protruding element. it is more prone to breakage and damage as compared to a conformal antenna. Since a PIFA can be easily flush-mounted on the surface of a vehicle, it will be a desirable alternative to a long whip antenna. We analyze the proposed antenna using high-frequency structure simulator 


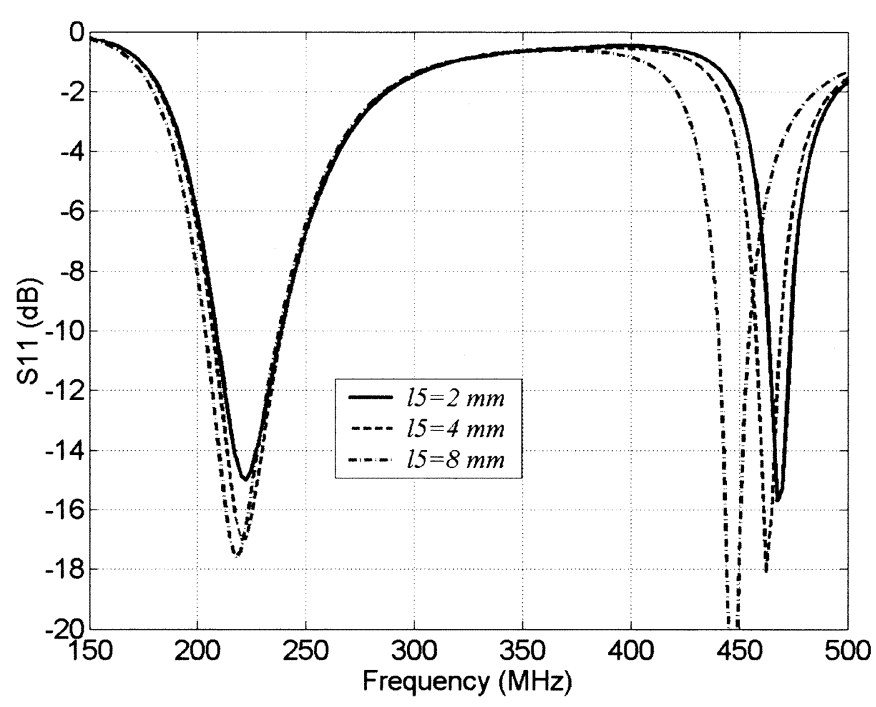

Fig. 6. Return loss versus frequency as function of the tuning leg $l_{5}$. Other parameters are $s_{1}=s_{3}=4 \mathrm{~cm}, s_{2}=10 \mathrm{~cm}, h=3.8 \mathrm{~cm}, s_{x}=3.5 \mathrm{~cm}$, $d_{1}=4 \mathrm{~cm}, d_{2}=4 \mathrm{~cm}, d_{3}=2 \mathrm{~cm}, l_{1}=8.4 \mathrm{~cm}, l_{2}=6 \mathrm{~cm}, l_{3}=7.26 \mathrm{~cm}$, $l_{4}=3.5 \mathrm{~cm}$, and $l_{6}=16 \mathrm{~cm}$.

(HFSS) [15]. Note that simulating an antenna on a vehicle at 900/1800 MHz using HFSS is a large computational problem that requires significant computational resources. This problem is avoided when the antenna is designed and operated at $225 / 450$ MHz.

\section{ANTENNA GEOMETRY}

The geometry of the proposed antenna is shown in Fig. 1. It consists of a rectangular element with a slot and two legs. The rectangular element with the slot being the larger element determines the resonance frequency for the low-frequency band (around $225 \mathrm{MHz}$ ). The incorporation of the slot provides an additional mechanism to adjust antenna tuning. The locations for the feed and shorting pin are shown in Fig. 1. In our HFSS model, the feed (a vertical lumped gap source referred to as $50 \Omega$ ) is at the center of a $0.5-\mathrm{cm}$ wide metal strip. The metal strip is on the $y z$ plane with its $y$ and $z$ dimensions being 0.5 and $h \mathrm{~cm}$, respectively. Similarly, the shorting pin is also made of a metal plate of width of $5 \mathrm{~cm}$ and is on the $y z$ plane. In a practical application, the feed will originate from the radiofrequency (RF) signal pad on the ground plane. The shorting pin, on the other hand, will be directly connected to the ground pad on the ground plane.

As a starting point, a ground plane with the dimensions of 50 $\mathrm{cm}$ by $30 \mathrm{~cm}$ is considered (see Fig. 2). The reason for choosing a ground plane of this size was to reduce computational time. The larger the ground plane, the more the number of tetrahedral cells and since the simulations were to be carried out over a frequency range of $150-500 \mathrm{MHz}$, computational time would have been prohibitively large. Nevertheless, prior to putting the antenna on two types of vehicles, it was simulated on a $150 \mathrm{~cm}$ by $150 \mathrm{~cm}$ ground plane to reconfirm performance data. We consider that the ground plane is infinitely thin and that the antenna and ground-plane materials are made of perfect electric conductors.

Simulations were conducted using HFSS within the frequency range of 150-500 MHz. Convergence was tested for

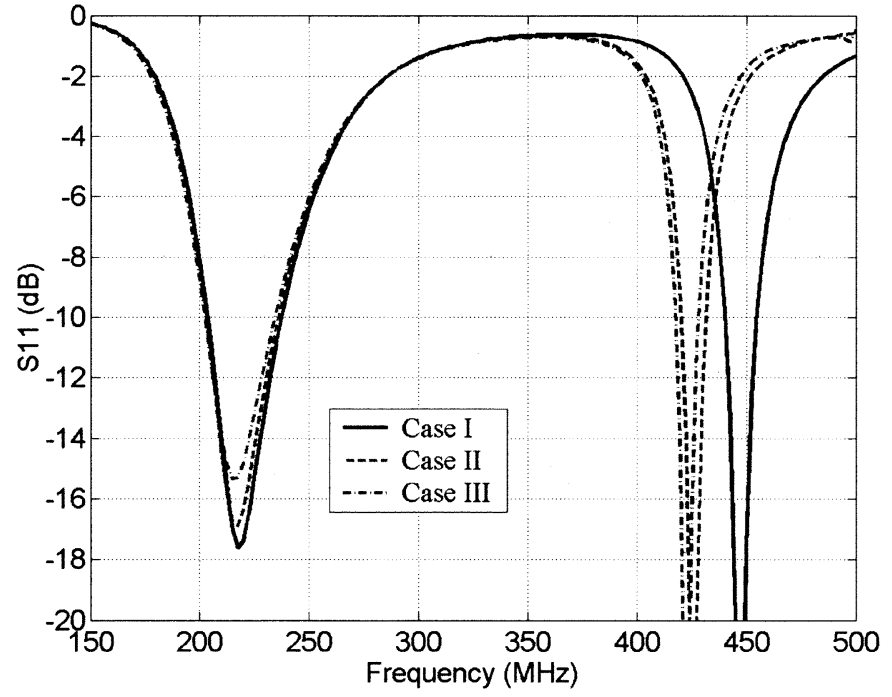

Fig. 7. Computed return loss data for cases I, II, and III, representing adjustment of the high-band leg. Other parameters are $s_{1}=6 \mathrm{~cm}$, $s_{2}=10 \mathrm{~cm}, h=3.8 \mathrm{~cm}, s_{x}=3.5 \mathrm{~cm}, d_{1}=4 \mathrm{~cm}, d_{2}=4 \mathrm{~cm}, d_{3}=2 \mathrm{~cm}$, $l_{5}=8 \mathrm{~cm}$, and $l_{6}=16 \mathrm{~cm}$.

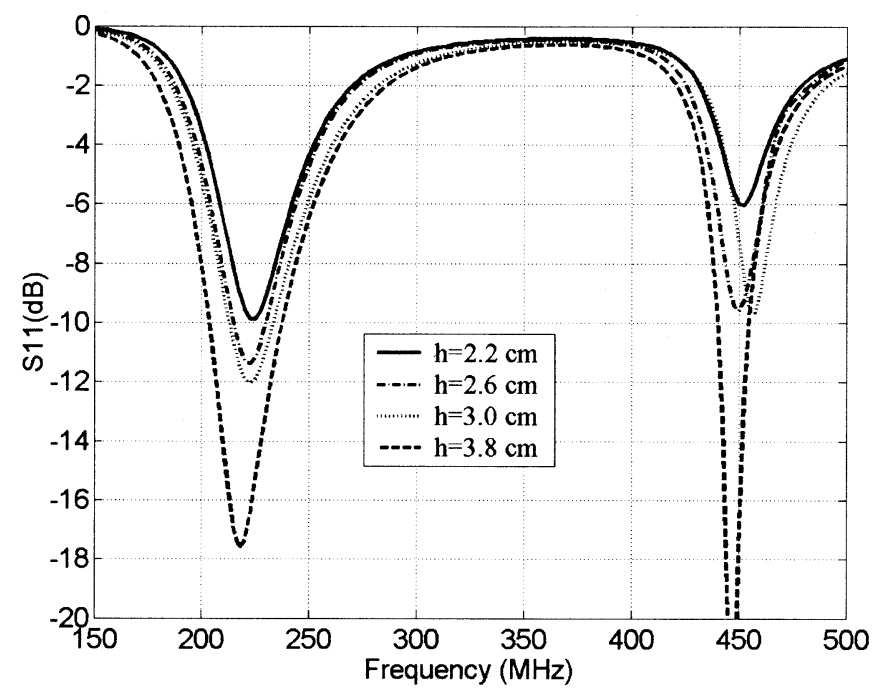

Fig. 8. Computed return loss data with antenna height $h$ as the parameter. Other parameters are $s_{1}=s_{3}=4 \mathrm{~cm}, s_{2}=10 \mathrm{~cm},, s_{x}=3.5 \mathrm{~cm}, d_{1}=$ $4 \mathrm{~cm}, d_{2}=4 \mathrm{~cm}, d_{3}=2 \mathrm{~cm}, l_{1}=8.4 \mathrm{~cm}, l_{2}=6 \mathrm{~cm}, l_{3}=7.26 \mathrm{~cm}$, $l_{4}=3.5 \mathrm{~cm}, l_{5}=8 \mathrm{~cm}$, and $l_{6}=16 \mathrm{~cm}$.

each model separately in terms of evaluating S11 (decibel) at a single frequency for a number of times. Once convergence was obtained, simulations were conducted in order to obtain swept frequency response extending from 150 to $500 \mathrm{MHz}$. The swept response gave us the S11 data, which was used to plot return loss and impedance. Radiated fields were computed at 225 and $450 \mathrm{MHz}$, which are the center frequencies of the two bands under consideration here.

\section{COMPUTATIONAL Results}

\section{A. Characteristics and Tuning}

Computed return loss data versus frequency for the proposed antenna is shown in Fig. 3. For comparison, a conventional PIFA consisting of a rectangular metal element with dimensions of 18 $\mathrm{cm}$ by $24 \mathrm{~cm}$ was also simulated. Two cases for the R-shaped 


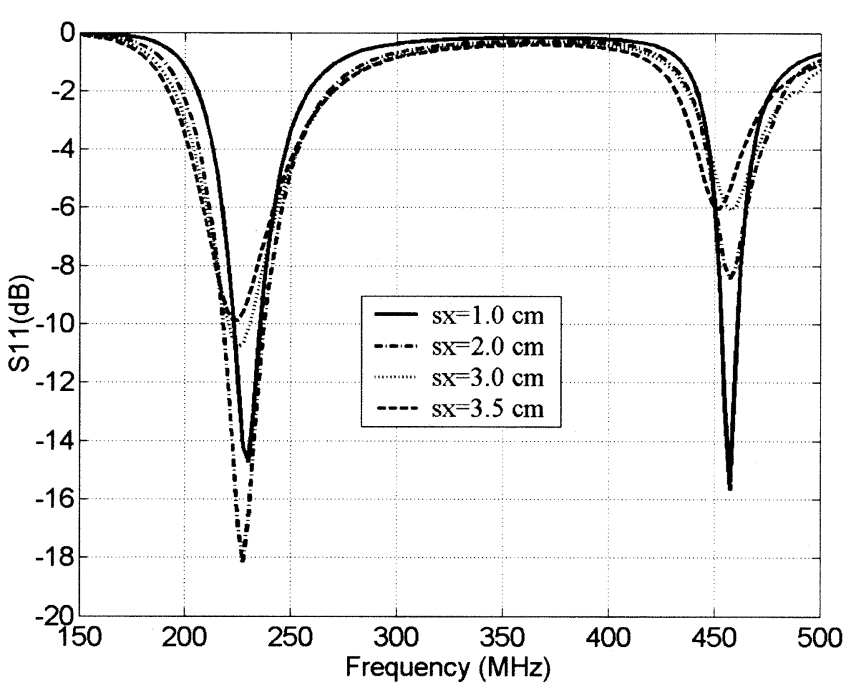

Fig. 9. Computed return loss data versus frequency with feed to shorting pin spacing $s_{x}$ as the parameter. Other parameters are $s_{1}=s_{3}=4 \mathrm{~cm}, s_{2}=$ $10 \mathrm{~cm}, h=2.2 \mathrm{~cm}, d_{1}=4 \mathrm{~cm}, d_{2}=4 \mathrm{~cm}, d_{3}=2 \mathrm{~cm}, l_{1}=8.4 \mathrm{~cm}$, $l_{2}=6 \mathrm{~cm}, l_{3}=7.26 \mathrm{~cm}, l_{4}=3.5 \mathrm{~cm}, l_{5}=8 \mathrm{~cm}$, and $l_{6}=16 \mathrm{~cm}$.

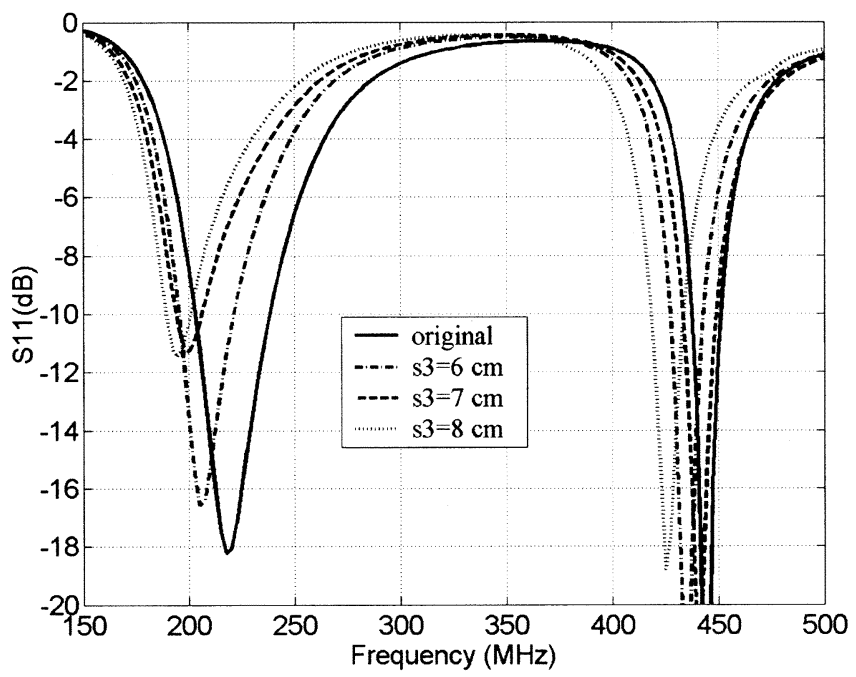

Fig. 10. Computed return loss data versus frequency with $s_{3}$ as the parameter. Other parameters are $s_{1}=4 \mathrm{~cm}, s_{2}=10 \mathrm{~cm}, h=3.8 \mathrm{~cm}, s_{x}=3.5 \mathrm{~cm}$, $d_{1}=4 \mathrm{~cm}, d_{2}=4 \mathrm{~cm}, d_{3}=2 \mathrm{~cm}, l_{1}=8.4 \mathrm{~cm}, l_{2}=6 \mathrm{~cm}, l_{3}=7.26 \mathrm{~cm}$, $l_{4}=3.5 \mathrm{~cm}, l_{5}=8 \mathrm{~cm}$, and $l_{6}=16 \mathrm{~cm}$.

PIFA were simulated, one consisting of a 2-cm-wide slot $\left(s_{2}=\right.$ $2 \mathrm{~cm}, s_{1}=s_{3}=8 \mathrm{~cm}$ ) while the other consisting of a $10-\mathrm{cm}$ wide slot $\left(s_{2}=10 \mathrm{~cm}, s_{1}=s_{3}=4 \mathrm{~cm}\right)$. The antenna height and other parameters were fixed. From Fig. 3, it is apparent that the rectangular PIFA is resonant at a single frequency (around $210 \mathrm{MHz}$ ), as expected. The proposed R-shaped PIFA resonates at two distinct frequencies at around 225 and $445 \mathrm{MHz}$. Note that increasing the slot from 2 to $10 \mathrm{~cm}$ reduces the resonance frequency slightly.

Based on the computational data, a prototype antenna was fabricated and measured. The antenna prototype built had the same parameters as the 10-cm slot R-PIFA. Measured return loss data are shown in Fig. 3; the agreement between the measured and computed data is good. Computed and measured resonant frequencies are close and the measured bandwidths in

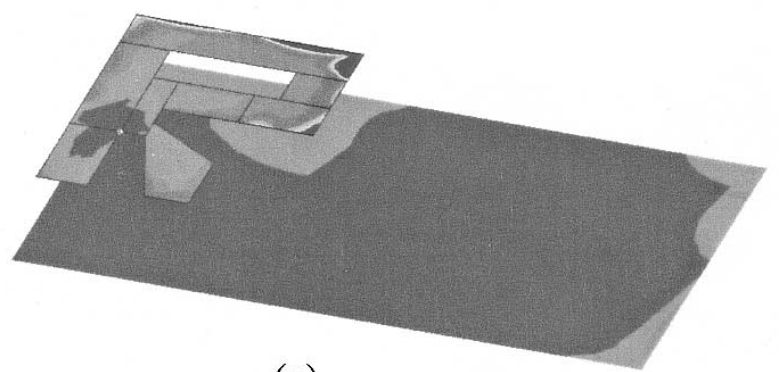

(a)

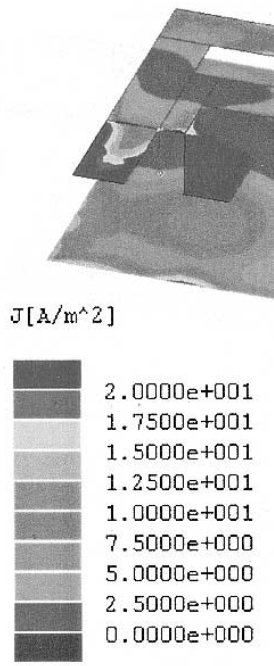

Fig. 11. Current distribution at (a) 225 and (b) $450 \mathrm{MHz}$. Other parameters are $s_{1}=6 \mathrm{~cm}, s_{2}=10 \mathrm{~cm}, h=3.8 \mathrm{~cm}, s_{x}=3.5 \mathrm{~cm}, d_{1}=4 \mathrm{~cm}, d_{2}=4 \mathrm{~cm}$, $d_{3}=2 \mathrm{~cm}, l_{1}=8.4 \mathrm{~cm}, l_{2}=6 \mathrm{~cm}, l_{3}=7.26 \mathrm{~cm}, l_{4}=3.5 \mathrm{~cm}, l_{5}=8 \mathrm{~cm}$, and $l_{6}=16 \mathrm{~cm}$.

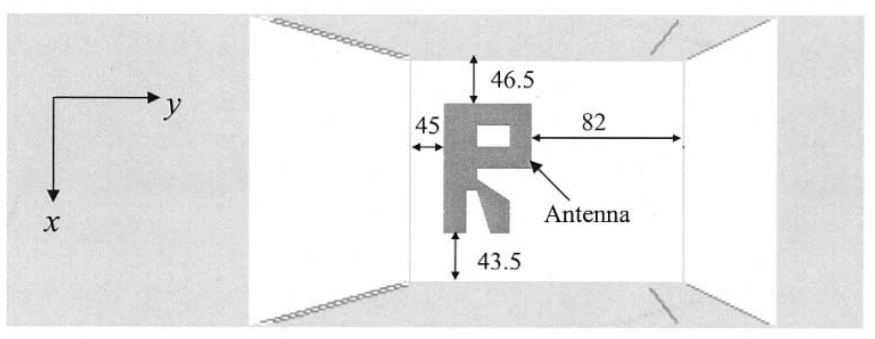

(a) R-Shaped PIFA (magnified) on a Mitsubishi Lancer Cedia. Dimensions in (cm).

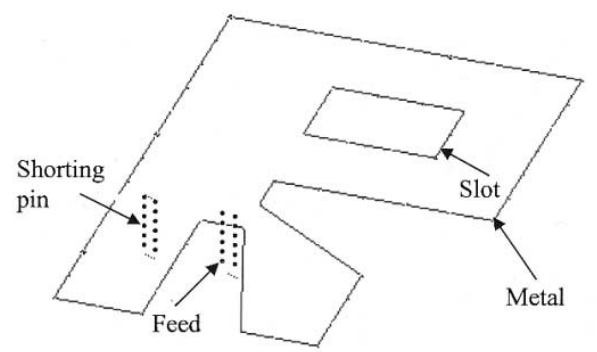

(b) HFSS Model of R-Shaped PIFA.

Fig. 12. Vehicle model with roof-mounted antenna.

both bands are also in good agreement with the computed bandwidths.

Computed input-impedance data for the above cases are shown on the Smith chart in Fig. 4. Note that the conventional PIFA shows one resonance, as indicated by the solid line (it 


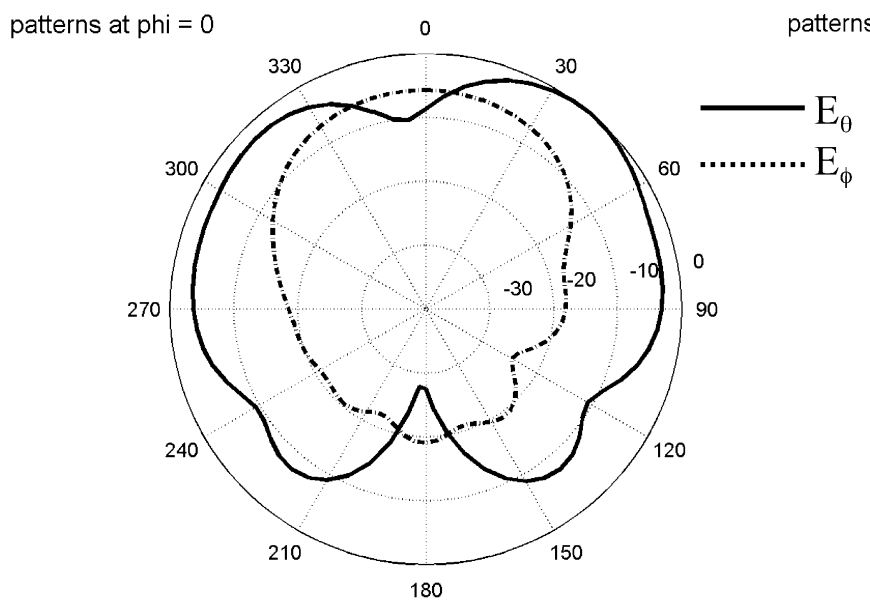

(a)

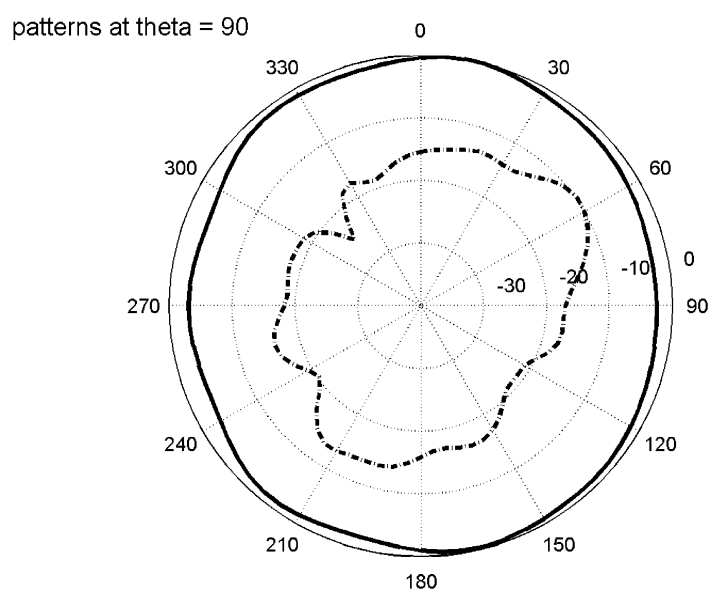

(c)

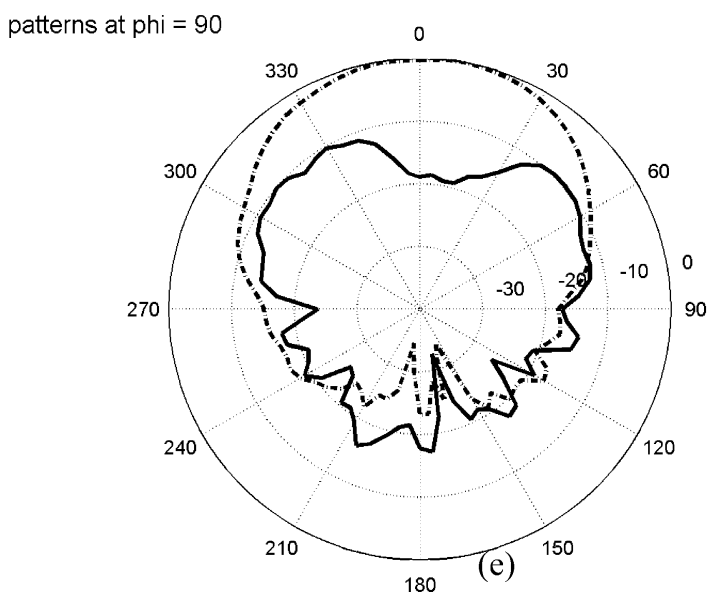

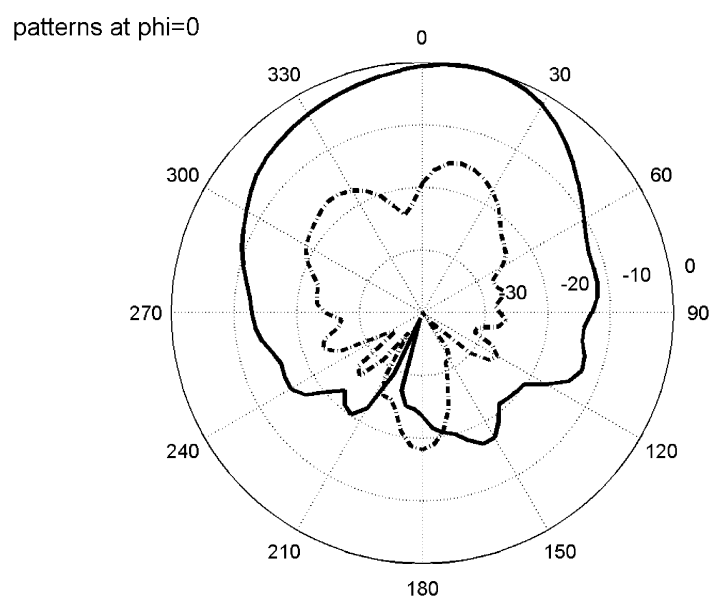

(d)

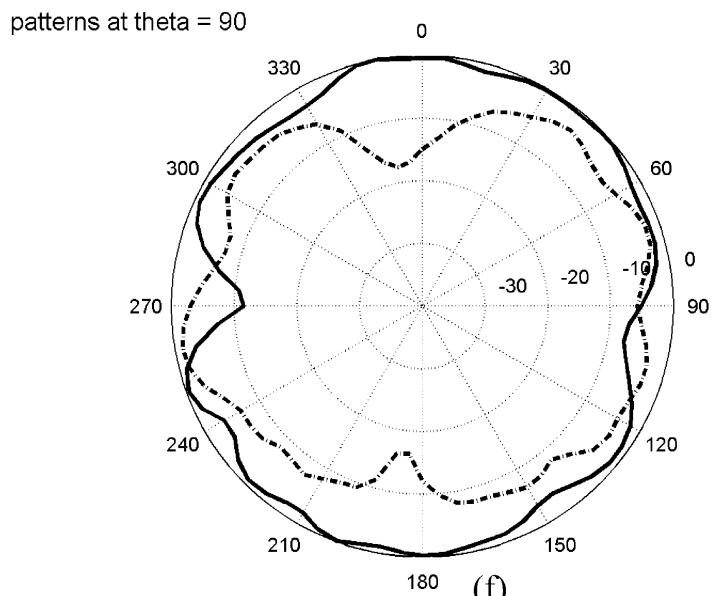

(f)

Fig. 13. Radiation patterns on Mitsubishi Lancer Cedia at (a) $225 \mathrm{MHz}\left(\phi=0^{\circ}\right)$, (b) $225 \mathrm{MHz}\left(\phi=90^{\circ}\right)$, (c) $225 \mathrm{MHz}\left(\theta=90^{\circ}\right)$, (d) $450 \mathrm{MHz}\left(\phi=0^{\circ}\right)$, (e) $450 \mathrm{MHz}\left(\phi=90^{\circ}\right)$, and (f) $450 \mathrm{MHz}\left(\theta=90^{\circ}\right)$.

passes the center region of the Smith chart only once). In contrast, the R-shaped PIFA shows the presence of two resonances (both the 2 and 10-cm-wide slots) that pass the center region of the Smith chart twice representing dual-band characteristics.
Computed input-impedance data for the R-shaped PIFA with and without the presence of the high-band leg are shown in Fig. 5(a). Note that the high-band leg shown in Fig. 1 has been removed for this case. It is apparent that the impedance 
locus "without the high-band leg" passes the center region of the Smith chart only once, indicating single-band response. With the proposed R-shaped PIFA, the impedance locus passes the center region of the Smith chart twice, which indicates a dual-band response. Thus, it is clearly the presence of the high-band leg that results in dual-band response. This can be further confirmed from the return loss plots of Fig. 5(b).

Computed return loss data versus frequency with the length of the tuning leg $\left(l_{5}\right)$ as the parameter are shown in Fig. 6. Here, $l_{5}$ has been adjusted as 2,4 , and $8 \mathrm{~cm}$, respectively. It is evident that by adjusting $l_{5}$, the resonance frequency of the high band can be adjusted. Increasing $\left(l_{5}\right)$ also improves the tuning of the high band (it reduces $\mathrm{S} 11$ even further and broadens achievable bandwidth). Increasing $l_{5}$ reduces the resonance frequency of the low band slightly and improves the tuning of the low band.

The effect of changing the dimensions of the high-band leg is demonstrated in Fig. 7. Three cases are considered, as follows:

1) case I $\left(l_{1}=8.4 \mathrm{~cm}, l_{2}=6 \mathrm{~cm}, l_{3}=7.26 \mathrm{~cm}, l_{4}=\right.$ $3.5 \mathrm{~cm}$, and $\left.l_{6}=16 \mathrm{~cm}\right)$;

2) case II $\left(l_{1}=8.4 \mathrm{~cm}, l_{2}=5.0 \mathrm{~cm}, l_{3}=9.1 \mathrm{~cm}, l_{4}=\right.$ $3.5 \mathrm{~cm}$, and $\left.l_{6}=16 \mathrm{~cm}\right)$

3) case III ( $l_{1}=8.4 \mathrm{~cm}, l_{2}=1.0 \mathrm{~cm}, l_{3}=16.3 \mathrm{~cm}, l_{4}=$ $3.5 \mathrm{~cm}$, and $\left.l_{6}=16 \mathrm{~cm}\right)$.

The resonance frequencies for cases I, II, and III for the low band are 217, 217, and $215 \mathrm{MHz}$, respectively. The same for the high band are 447, 425, and 422, MHz respectively. It is clear that for both cases II and III, the resonance frequency decreases in the high band because the dimension of the high-band leg has increased. The effect on the low-band resonance frequency is minimal.

Computed return loss data as function of frequency with the antenna height $h$ as the parameter are shown in Fig. 8. Clearly, increasing the antenna height improves the bandwidth. If we consider $-10 \mathrm{~dB}$ as the limit, we see that the antenna provides best bandwidth when the antenna height is the largest. This is very common with PIFAs. An increase in antenna height also makes a small reduction in antenna resonance frequency, as apparent from Fig. 8. This happens because the antenna electrical length becomes longer as height is increased.

Another method of changing antenna tuning is demonstrated in Fig. 9. Computed return loss data as a function of frequency are shown in Fig. 9 with the feed to shorting pin spacing $s_{x}$ as the parameter. We consider an antenna height, $h$ of $2.2 \mathrm{~cm}$. Note that this antenna height resulted in rather poor tuning in Fig. 8. The purpose of this exercise is to show that a poor tuning can be improved by adjusting $s_{x}$. As is clear from Fig. 9, reducing $s_{x}$ for this case improves antenna tuning. However, clearly, since most application platforms have predefined bandwidth requirements, the design should proceed to meet that requirement. Antenna height offers the primary control on bandwidth with feed to shorting pin spacing $s_{x}$ offering additional control.

Next, computed return loss data versus frequency with $s_{3}$ as the parameter are shown in Fig. 10. Note that $s_{3}$ indicates the dimension on the right-hand side (RHS) of Fig. 1. Clearly, increasing this dimension the resonance frequency of the low band is affected more than the high band. The resonance frequency decreases with increase in $s_{3}$, as expected.

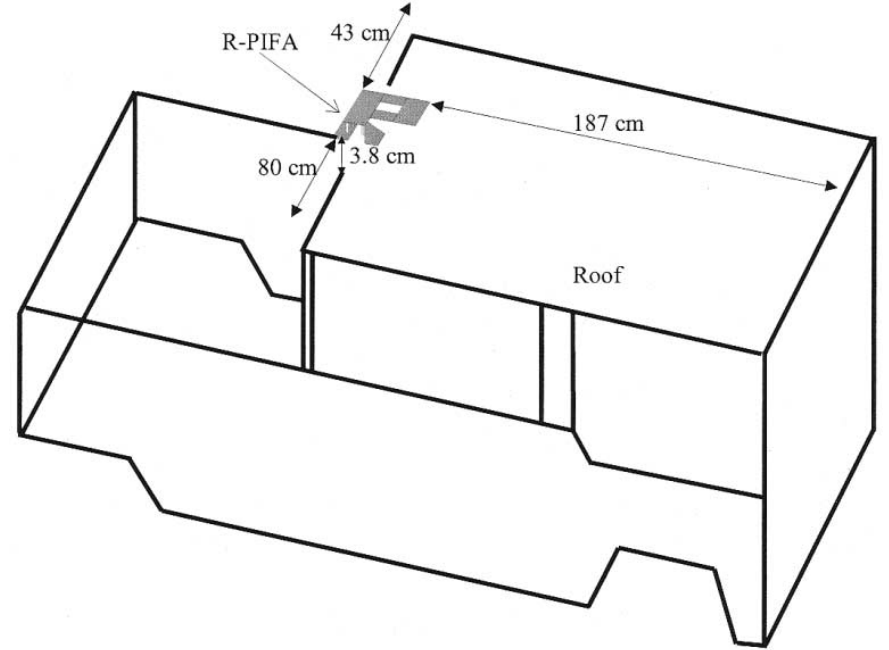

Fig. 14. Jeep Wrangler with R-PIFA.

\section{B. Current Distribution}

Computed current distribution for the proposed R-shaped PIFA at 225 and $450 \mathrm{MHz}$ are shown in Fig. 11(a) and (b). Note that at $225 \mathrm{MHz}$ current intensity is high on the low-band leg. Current intensity at this frequency is low on the high-band and tuning legs. From Fig. 11(b), current intensity for 450 $\mathrm{MHz}$ is very high on the high-band leg and is also high on the tuning leg. It is also interesting to note that at this frequency there is reasonably strong current flow on the low-band leg as well. Thus, the current distribution data presented here clearly indicate the functions of each arm at their respective operating frequencies.

\section{Radiation Characteristics}

Since the R-shaped PIFA has been proposed for vehicular application, we simulated its characteristics on a large ground plane also $(150 \mathrm{~cm}$ by $150 \mathrm{~cm}$ larger than $1 \lambda$ by $1 \lambda$ at $225 \mathrm{MHz})$. It was observed that the effect of the large ground plane on the resonance frequency was negligible. The tuning in the high band remained virtually unaffected. The low-band tuning degraded slightly as ground plane size was increased. The antenna parameters were then adjusted $\left(s_{1}=1 \mathrm{~cm}, s_{2}=16 \mathrm{~cm}, s_{3}=1 \mathrm{~cm}\right.$, $s_{x}=2 \mathrm{~cm}, d_{1}=4 \mathrm{~cm}, d_{2}=4 \mathrm{~cm}, d_{3}=2 \mathrm{~cm}, l_{1}=8.4 \mathrm{~cm}$, $l_{2}=6.4 \mathrm{~cm}, l_{3}=6.6 \mathrm{~cm}$, and $l_{4}=3 \mathrm{~cm}$ ) to improve the tuning in the low band.

Next, we computed the radiation characteristics of the R-shaped PIFA on two vehicles. The first vehicle modeled was a Mitsubishi Lancer Cedia [16] with length $=448 \mathrm{~cm}$, width $=169.5 \mathrm{~cm}$, and height $=143 \mathrm{~cm}$. The R-shaped PIFA was on the roof of the vehicle, as shown in Fig. 12. Computed normalized radiation patterns for this simple vehicle model are shown in Fig. 13. Fig. 13(a) ( $x z$ plane, $\phi=0^{\circ}$ plane), (b) ( $y z$ plane, $\phi=90^{\circ}$ plane), and (c) ( $x y$ plane, $\theta=90^{\circ}$ plane) indicate patterns at $225 \mathrm{MHz}$, the center of the low band. Similarly, Fig. 13(d), (e), and (f) represent patterns at $450 \mathrm{MHz}$, the center of the high-frequency band.

From Fig. 13(a) and (b), it is apparent that the $E_{\theta}$ component is the dominant field component here and the peak of the $E_{\phi}$ 


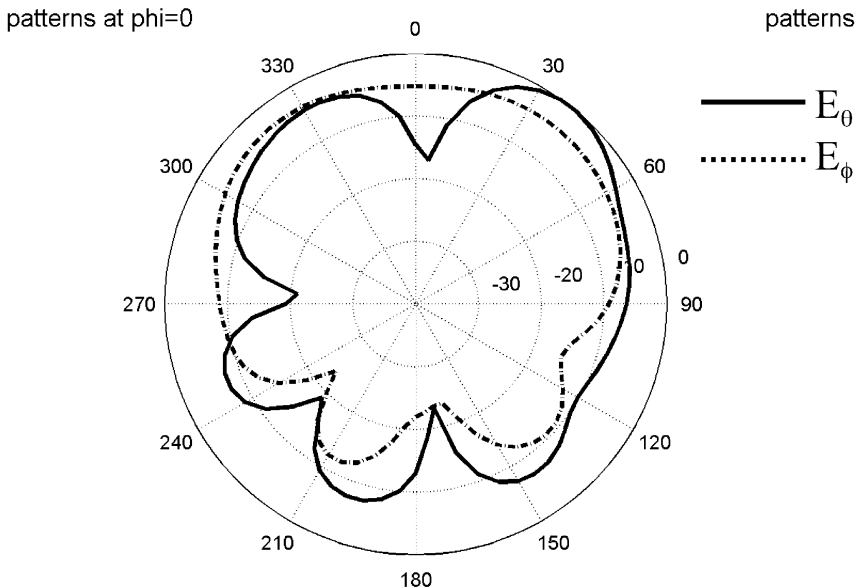

(a)

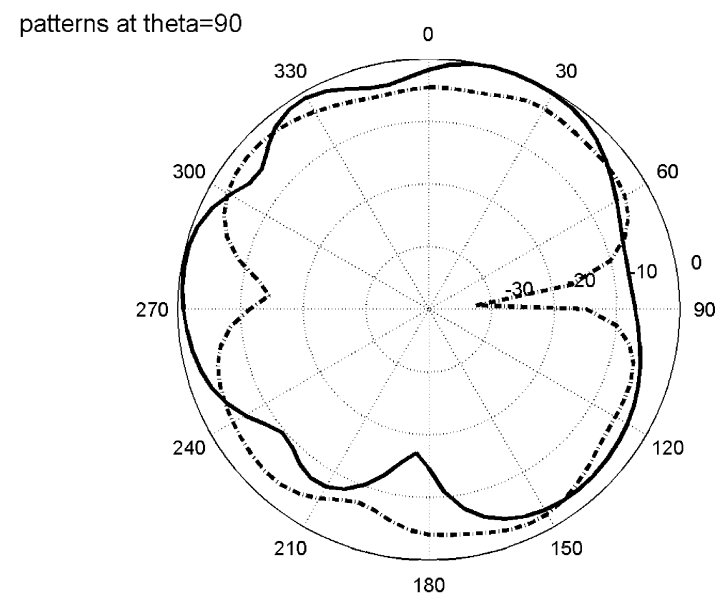

(c)

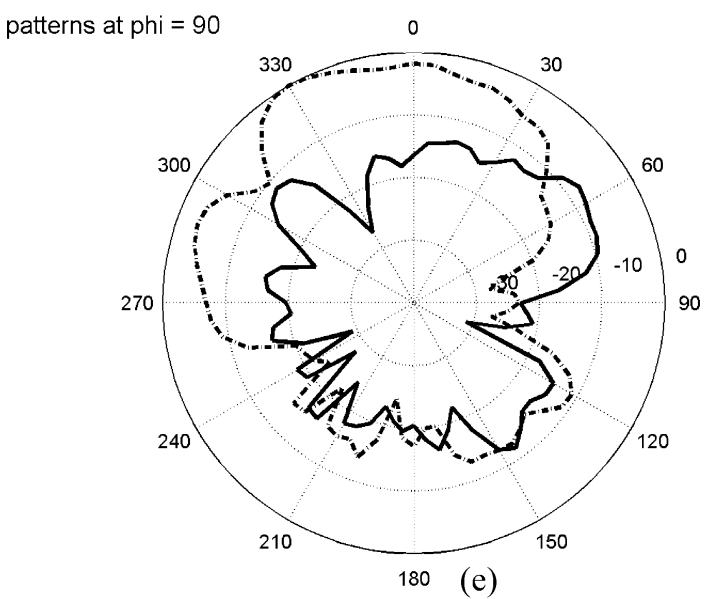

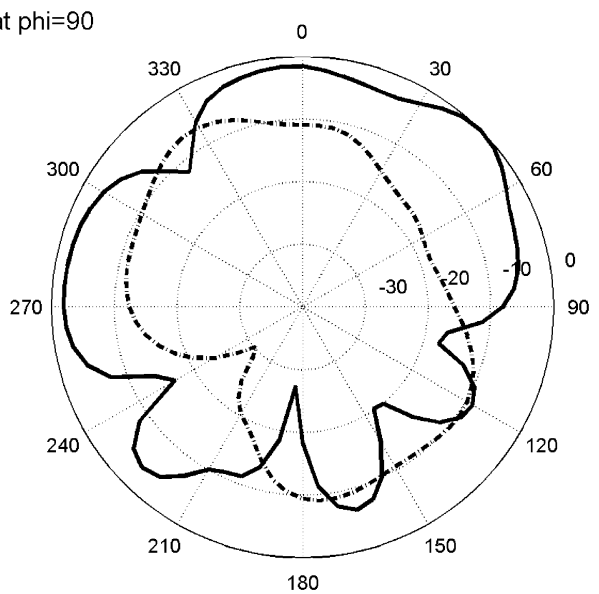

(b)

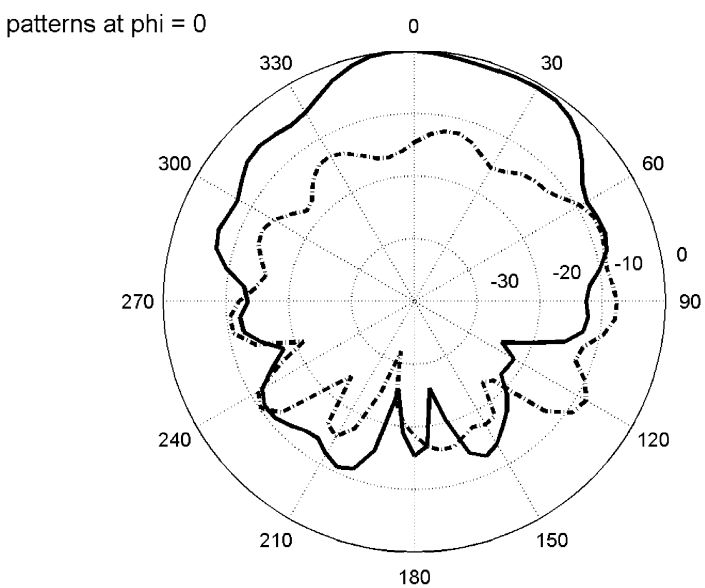

(d)

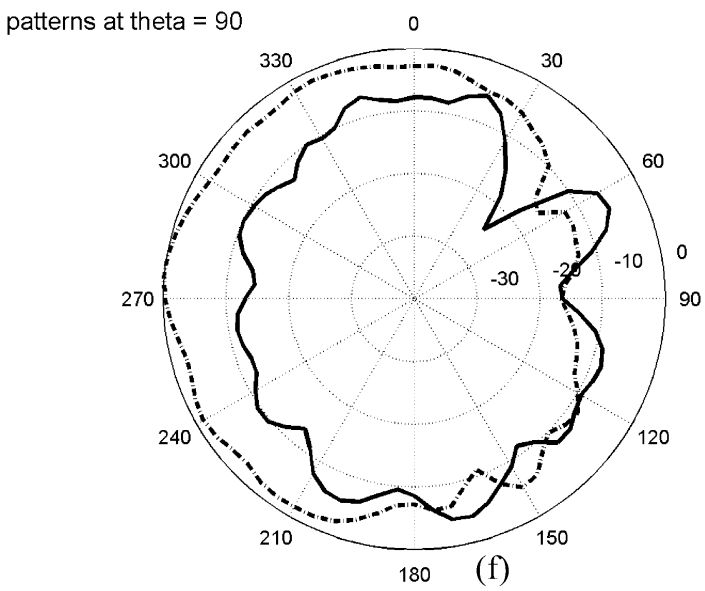

Fig. 15. Radiation patterns on a Jeep Wrangler at (a) $225 \mathrm{MHz}\left(\phi=0^{\circ}\right)$, (b) $225 \mathrm{MHz}\left(\phi=90^{\circ}\right)$, (c) $225 \mathrm{MHz}\left(\theta=90^{\circ}\right)$, (d) $450 \mathrm{MHz}\left(\phi=0^{\circ}\right)$, (e) 450 $\mathrm{MHz}\left(\phi=90^{\circ}\right)$, and (f) $450 \mathrm{MHz}\left(\theta=90^{\circ}\right)$.

component is at least $6 \mathrm{~dB}$ below the peak of the $E_{\theta}$ component. The peak gain due to $E_{\theta}$ is only approximately $3.5 \mathrm{dBi}$ (along $\theta=40^{\circ}$ ). Gain in the $\theta=0^{\circ}$ direction is $-6.5 \mathrm{dBi}$. Observing the $E_{\theta}$ components of Fig. 13(a) and (b), it is clear that the radiation intensity along $\theta=90^{\circ}$ is just below approximately 2 $\mathrm{dB}$ of that of the peak radiation intensity. Thus, the gain in the 
horizontal plane is about $1.5 \mathrm{dBi}$. The pattern coverage in the horizontal plane can be visualized from Fig. 13(c). Clearly, the $E_{\theta}$ component is very nearly uniform in this plane.

In addition, from Fig. 13(a) and (b) in the direction of the ground $\left(\theta=180^{\circ}\right)$, the radiation intensity is 20 to $27 \mathrm{~dB}$ below that of the peak. These patterns look similar to the patterns of a loop antenna [17] and also to the patterns of a vertical monopole antenna on a finite ground plane. A monopole on a finite ground plane has a null along $\theta=0^{\circ}$ in its elevation plane pattern and the directions of its two peaks are along $\theta=60^{\circ}$ and $\theta=240^{\circ}$ [17]. The current on the tip of a monopole antenna is zero $\left(\theta=0^{\circ}\right)$, which results in zero fields. The proposed R-shaped PIFA has nonzero fields along $\theta=0^{\circ}$ due to nonzero current on the antenna. Thus, the R-shaped PIFA should provide better coverage in the upper hemisphere as compared to vertical monopole antenna.

Computed patterns at $450 \mathrm{MHz}$ demonstrate significant amount of directionality [Figs. 13(d) and (e)]. The $E_{\theta}$ component is the dominant component in the $\phi=0^{\circ}$ plane while the $E_{\phi}$ component is the dominant component in the $\phi=90^{\circ}$ plane. The peak gain is about $7.5 \mathrm{dBi}$ and the front-to-back ratio is $22 \mathrm{~dB}$. The $3-\mathrm{dB}$ beamwidth is $70^{\circ}$. Beamwidth corresponding to $0 \mathrm{dBi}$ gain is $120^{\circ}$. The $x y$ plane pattern at 450 $\mathrm{MHz}$ for the proposed antenna is shown in Fig. 13(f). Note that, unlike the $x y$ plane pattern at $225 \mathrm{MHz}$, here the gain in the horizontal plane is much less. Thus, at $450 \mathrm{MHz}$ the design is clearly suitable for directional communication targeted toward the upper hemisphere.

As mentioned, the proposed antenna was also simulated on the roof of a Jeep Wrangler [18]. The R-shaped PIFA was placed at one edge of the roof (see Fig. 14). The vehicle and the roof were modeled using perfect electric conductors. Fig. 15(a) ( $x z$ plane, $\phi=0^{\circ}$ plane), (b) ( $y z$ plane, $\phi=90^{\circ}$ plane), and (c) ( $x y$ plane, $\theta=90^{\circ}$ plane) indicate patterns at $225 \mathrm{MHz}$, the center of the low band. Similarly, Fig. 15(d), (e), and (f) represent patterns at $450 \mathrm{MHz}$, the center of the high-frequency band. Patterns in Fig. 15 are generally comparable to those in Fig. 13, with the latter ones showing effects due to reflection and diffraction. This is clearly the result of the antenna being positioned at one edge of the roof. Note that omnidirectionality is not as apparent [see Fig. 15(c)], as it was before [Fig. 13(c)]. Patterns at $450 \mathrm{MHz}$ show directionality with signs of reflection and diffraction.

\section{DISCUSSION AND CONCLUSION}

A dual-band R-shaped planar inverted-F antenna is introduced. The antenna consists of closely coupled radiating elements that enable it to operate in two different frequency bands. The antenna is analyzed using HFSS and the proposed antenna operates in 225- and $450-\mathrm{MHz}$ bands. However, with proper scaling this antenna may be suitable for dual-band GSM 900/1800 MHz phone applications. Parametric data such as return loss, input impedance, and radiation pattern are presented, along with clear guidelines on how to design the antenna.

Since the antenna has been designed for operation on a vehicle, the effect of the ground plane on its bandwidth, radiation pattern, and efficiency should be minimal because the groundplane size available on a vehicle roof surface is quite large as compared to the ground plane available for PIFAs for mobile phones. Simulations performed on $50 \mathrm{~cm}$ by $30 \mathrm{~cm}$ and $150 \mathrm{~cm}$ by $150 \mathrm{~cm}$ ground planes support this conclusion. It was observed that the effect of the large ground plane on the resonance frequency was also negligible.

To our knowledge, it is not directly possible to get efficiency data from HFSS models. However, we have provided gain data for the proposed antenna instead of efficiency. Peak gain at 225 $\mathrm{MHz}$ is $3.5 \mathrm{dBi}$ and at $450 \mathrm{MHz}$ it is $7.5 \mathrm{dBi}$. Since $G=e D$ ( $G=$ gain, $e=$ efficiency, and $D=$ directivity) and directivity data are very close to gain data, the efficiency of the R-PIFA is close to $100 \%$ when the return loss is less than $10 \mathrm{~dB}$ (considering that the losses due to conductor is minimal and that the dielectric losses are negligible).

\section{REFERENCES}

[1] M. A. Jensen and Y. Rahmat-Samii, "Performance analysis of antennas for hand-held transceivers using FDTD," IEEE Trans. Antennas Propoagat., vol. 42, pp. 1106-1113, Aug. 1994.

[2] C. R. Rowell and R. D. Murch, "A capacitively loaded PIFA for compact mobile telephone handsets," IEEE Trans. Antennas Propagat., vol. 45, pp. 837-842, May 1997.

[3] L. Z. Dong, P. S. Hall, and D. Wake, "Dual-frequency planar inverted-F antennas," IEEE Trans. Antennas Propagat., vol. 45, pp. 1451-1458, Oct. 1997.

[4] K. L. Virga and Y. Rahmat-Samii, "Low-profile enhanced-bandwidth PIFA antennas for wireless communications packaging," IEEE Trans. Microwave Theory Tech., vol. 45, pp. 1879-1888, Oct. 1997.

[5] C. R. Rowell and R. D. Murch, "A compact PIFA suitable for dual-frequency 900/1800-MHz operation," IEEE Trans. Antennas Propoagat., vol. 46, pp. 596-598, Apr. 1998.

[6] J. T. Rowley and R. B. Waterhouse, "Performance of shorted microstrip patch antennas for mobile communications handsets at $1800 \mathrm{MHz}$," IEEE Trans. Antennas Propagat., vol. 47, pp. 815-822, May 1999.

[7] P. Salonen, M. Kaskilammi, and M. Kivikosi, "Single-fed dual-band planar inverted-F antenna with U-shaped slot," IEEE Trans. Antennas Propagat., vol. 48, pp. 1262-1264, Aug. 2000.

[8] M.-S. Tong, M. Yang, Y. Chen, and R. Mittra, "Finite-difference time-domain analysis of a stacked dual-frequency microstrip planar inverted-F antenna for mobile telephone handsets," IEEE Trans. Antennas Propagat., vol. 49, pp. 367-376, Mar. 2001.

[9] S. C. K. Ko and R. D. Murch, "Compact integrated diversity antenna for wireless communications," IEEE Trans. Antennas Propagat., vol. 49, pp. 954-960, June 2001.

[10] G. K. H. Lui and R. D. Murch, "Compact dual-frequency PIFA designs using LC resonators," IEEE Trans. Antennas Propagat., vol. 49, pp. 1016-1019, July 2001.

[11] M. Ali, R. A. Sadler, and G. J. Hayes, "A uniquely packaged internal inverted-F antenna for Bluetooth or wireless LAN application," IEEE Antennas Wireless Propag. Lett., vol. 1, pp. 5-7, Jan. 2002.

[12] M. Ali and G. J. Hayes, "Analysis of integrated inverted-F antennas for Bluetooth applications," in Proc. IEEE Antennas Propagation Conf. Wireless Commun. Dig., Waltham, MA, Nov. 2000, pp. 21-24.

[13] _ " "A small printed integrated inverted-F antenna for Bluetooth application," Microwave Optical Technol. Lett., vol. 33, no. 5, pp. 347-349, 5, 2002.

[14] K. Fujimoto and J. R. James, Mobile Antenna Design Handbook. Norwood, MA: Artech House.

[15] High Frequency Structure Simulators (HFSS) (2001). [Online]. Available: www.ansoft.com

[16] Specifications of Mitsubishi Lancer Cedia [Online]. Available: http://www.mitsubishi-motors.co.jp/PRODUCTSS/cedia.html

[17] C. A. Balanis, Antenna Theory Analysis and Design, 2nd ed. New York: Wiley, 1997, pp. 641-642.

[18] Specifications of Jeep Wrangler [Online]. Available: http://www.jeep.com/wrangler/exterior/details.html 


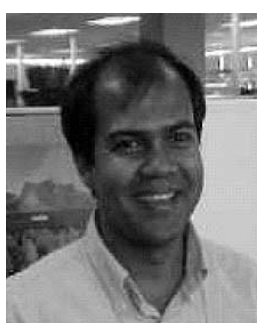

Mohammod Ali (M'93) received the B.Sc. degree in electrical and electronic engineering from the Bangladesh University of Engineering and Technology, Dhaka, in 1987. He received the M.A.Sc. and $\mathrm{Ph} . \mathrm{D}$. degrees, both in electrical engineering, from the University of Victoria, Victoria, BC, Canada in 1994 and 1997, respectively.

He was with the Bangladesh Institute of Technology, Chittagong, India, from 1988 to 1992 . From January 1998 to August 2001, he was with Ericsson Inc., Research Triangle Park, NC, first as a Staff Engineer and then as a Senior Staff Engineer. Since August 2001, he has been with the Department of Electrical Engineering, University of South Carolina, Columbia, as an Assistant Professor. He is the author or coauthor of more than 40 publications, has four U.S. patents issued in his name, and has several patent applications that are pending. His research interests include smart antennas, antenna miniaturization and reconfigurability, fractal and multiband antennas, electromagnetic bandgap materials, wireless sensors, and microwave circuits using wide bandgap materials.

Dr. Ali is the recipient of the 2003 National Science Foundation Faculty Career Award.

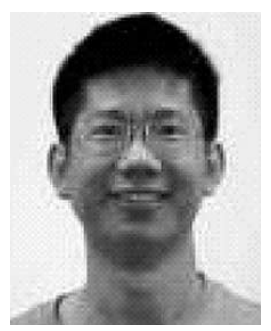

Guangli Yang was born in China in 1974. He received the B.S. degree in physics from Beijing University of Science and Technology, Beijing, China, in 1997 and the M.E. degree in computer engineering from the University of South Carolina (USC), Columbia, in 2003 . He is currently working toward the Ph.D. degree in electrical engineering at USC.

From 1997 to 2000, he worked on computer tomography for X-ray's nondestructive testing and circuit design for industrial cameras used in linear accelerator in Beijing. His current research interests include novel rectenna design for wireless microwave power transmission, RF circuits, circularly polarized microstrip patch antennas, and EBG structures.

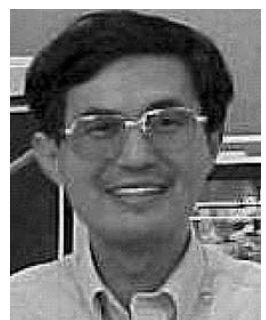

Huan-Sheng Hwang (M'93) received the M.S.E.E. and Ph.D. degrees from North Carolina State University, Raleigh, in 1993 and 1998, respectively.

In 1998, he joined Raychem Corp., Fuquay-Varina, $\mathrm{NC}$, where he served as $\mathrm{RF}$ engineer for research and development in RF and microwave circuits. Currently, he is with SonyEricsson Mobile Communications Inc., Research Triangle Park, $\mathrm{NC}$, as a Senior Staff Engineer for antenna design and research for cellular phones and wireless applications. He is also the coauthor of the chapter "Dielectric Slab Combiners" in a book entitled Active and Quasi-Optical Arrays for Solid-State Power Combing, New York: Wiley. His research interests include quasioptical and spatial power combining systems, antenna design, electromagnetics and wave propagations, $\mathrm{RF}$ and microwave/millimeter-wave components, and circuits.

Dr. Hwang won the Prestigious Bronze Medallion for Outstanding Scientific Achievement in 1996, presented at the 20th Army Science Conference.

Tuangsit Sittironnarit, photograph and biography not available at the time of publication. 